\title{
Determination of mycotoxin profiles characteristic of Alternaria strains isolated from Malbec grapes
}

\author{
Andrea Vargas Trinidad ${ }^{1}$, Fernando Quevedo Ganoza ${ }^{2}$, Virginia Fernández Pinto ${ }^{1}$, and Andrea Patriarca ${ }^{1}$ \\ ${ }^{1}$ PROPLAME, Department of Organic Chemistry, FCEN, Buenos Aires University, Argentina \\ ${ }^{2}$ CLEIBA, Faculty of Pharmacy and Biochemistry, National University of San Marcos, Peru
}

\begin{abstract}
The world grape production has increased, reaching 751 million quintals (Mql) in 2013. Many Alternaria species have been studied for their ability to produce secondary metabolites in foods, some of which have toxic properties with tenuazonic acid (TA), alternariol (AOH), alternariol methyl ether (AME) being the most important ones. The aim was to determine the characteristic mycotoxin production profiles of Alternaria strains isolated from Malbec grapes in the Patagonian region of Argentina. Fifty Alternaria isolates (5 A. alternata, 5 A. arborescens and 40 A. tenuissima) were analyzed for the production of mycotoxins (TA, AOH and AME) in autoclaved rice media by High Performance Liquid Chromatography (HPLC). All isolates were found to be producers of mycotoxins; the $100 \%$ was producer of TA $(0.016-21.031 \mathrm{mg} / \mathrm{kg}), 98 \% \mathrm{produced} \mathrm{AOH}$ $(0.003-0.057 \mathrm{mg} / \mathrm{kg})$ and $36 \%$ produced AME $(0.001-0.133 \mathrm{mg} / \mathrm{kg})$. Thirty-three isolates co-produced the three mycotoxins. In this study, it was demonstrated a high toxigenic potential of Alternaria isolates. Although Alternaria growth on grapes has been amply demonstrated, there are few studies about the incidence their more characteristic mycotoxin sand their toxicogenic capacity determination in grapes, wines and derivatives. In addition, mycotoxins studied in this work are not regulated in oenology. Therefore, further studies should be conducted to assess the health risk due to the presence of Alternaria toxins in grapes, wine, grape juice and raisins.
\end{abstract}

\section{Introduction}

World production of grapes, until 2013, was $751 \mathrm{Mql}$ and according to preliminary estimates of 2014 there were 271 million hl (Mhl) wine worldwide. Argentina reached a production of $15.2 \mathrm{Mhl}$, in the same period; the country is still considered the fifth largest producer of wines worldwide [1].

The genus Alternaria includes pathogenic species found in a variety of agronomically important plants such as cereals, oilseeds, vegetables and fruits [2]. A wide variety of Alternaria strains was isolated from different hosts including grapes [3-6]. Species such as Alternaria alternata, A. arborescens and A. tenuissima have frequently been isolated from grapes during development in the vineyard or postharvest storage [4,7-9].

Alternaria cause rot bunch damaged berries, scrape and pedicels [10,11]. From table grapes infected with A. alternata and cold storage, it was demonstrated that the pathogen is able to penetrate into the host tissue through the stomata and lenticels microcracks of the scarfskin [10].

The mycobiota frequently isolated from grapes includes the genera Aspergillus, Penicillium, Mucor, Rhizopus, Alternaria, Cladosporium, Botrytis and Fusarium [7,8, 12-25].

The main Alternaria mycotoxins belong to three structural classes: the tetramic acid derivative (TA), dibenzopyrone derivatives (AOH, AME and altenuene) and perylenquinone derivatives (Altertoxins: ALT) [26]. The most common toxins produced by this genus in foods are
$\mathrm{AOH}, \mathrm{AME}$ and TA. TA toxicity has been reported in plants, in chicken embryos and several other animal species, including guinea pigs, mice, rabbits, dogs and rhesus monkeys. AOH and AME are mutagenic and cytotoxic for bacterial and mammalian cells. TA presents higher acute toxicity than AOH, AME and ALT [27-32].

In foodstuffs, Alternaria mycotoxins can occur with other toxins produced by different genera. Theircooccurrence can contribute to an increase in the ingestion of mycotoxins in the human diet. Human exposure to these mycotoxins is difficult to assess since few data of their natural occurrence is available [32].

Globally, Alternaria has been isolated from grapes, wines, musts and raisins; however, the presence of their most common mycotoxins has rarely been studied in these substrates. There are not specific international regulations of Alternaria toxins in food.

The aim of this study was to determine the characteristic mycotoxin production profiles of Alternaria strains (TA, AOH and AME) isolated from Malbec grapes for wine production in the Patagonian region of Argentina.

\section{Materials and methods}

\subsection{Grape samples, isolation and identification of fungi}

A total of 10 samples of Malbec grapes (bunches) with and without apparent fungal contamination was analyzed. The samples were collected during the 2013 harvest 
from Maique and Azul valley in the Rio Negro province in Patagonian region of Argentina. Samples were sent to Food Microbiology Laboratory, FCEN, Buenos Aires University, where they were stored at $4^{\circ} \mathrm{C}$ until their analysis. A total of 95 Alternaria spp. isolates were obtained and identified from all grape samples [33]. Fifty Alternaria isolates (5 A. alternata, 5 A. arborescens and 40 A. tenuissima) were selected for the evaluation of mycotoxin production.

\subsection{Mycotoxin production}

The strains were cultured on autoclaved rice. Flasks containing $12.5 \mathrm{~g}$ of autoclaved polished rice were conditioned at $40 \%$ moisture. The rice was inoculated with a $5 \mathrm{~mm}$ disk cut from a colony margin (using a sterile cork borer) of 1-week-old Potato Carrot Agar (PCA) single spore culture and incubated at $25^{\circ} \mathrm{C}$ for 3 weeks in the dark [34].

\subsection{Extraction Alternaria toxins}

The culture material $(5 \mathrm{~g})$ was homogenized with $10 \mathrm{~mL}$ of methanol and $8 \mathrm{~mL}$ of $20 \%$ ammonium sulfate and filtered. The filtrate was extracted with $6 \mathrm{~mL}$ of hexane and the aqueous phase was divided into two parts. One part was extracted twice with $1 \mathrm{~mL}$ of chloroform. The organic phases were combined, evaporated to dryness and dissolved in $1 \mathrm{~mL}$ of methanol for $\mathrm{AOH}$ and $\mathrm{AME}$ analysis by HPLC. The other part was adjusted to $\mathrm{pH} 2$ with $6 \mathrm{~N} \mathrm{HCl}$ and extracted twice for TA with $5 \mathrm{~mL}$ of chloroform. The chloroformic phase was then partitioned into $6 \mathrm{~mL}$ of $5 \%$ sodium bicarbonate, acidified to $\mathrm{pH} 2$ again, and extracted twice with $3 \mathrm{~mL}$ of chloroform. The final chloroform extracts were combined, washed with $5 \mathrm{~mL}$ water, and evaporated to dryness. The residue was dissolved in $1 \mathrm{~mL}$ methanol and analyzed for TA by HPLC [34].

\subsection{HPLC detection}

The extracts obtained were analyzed by HPLC. The HPLC system consisted of a Shimadzu LC-142 CA liquid chromatograph (Shimadzu, Kyoto, Japan) equipped with a Rheodyne sample valve fitted with a $20 \mu$ l loop and a Shimadzu SPD M10Avp UV photodiode array detector. The analytical column was Jupiter $4.6 \times 250 \mathrm{~mm} 5 \mu$ C18 (Phenomenex, USA). Standards of TA (as a copper salt), AME and AOH were purchased from SIGMA Chemical Company (St. Louis, MO, USA). The mobile phase was methanol/water (80:20) containing $300 \mathrm{mg}$ $\mathrm{ZnSO}_{4} \cdot \mathrm{H}_{2} \mathrm{O} / \mathrm{L}$, for $\mathrm{AME}$ and $\mathrm{AOH}$, and methanol/water (90:10) containing $300 \mathrm{mg} \mathrm{ZnSO}_{4} \cdot \mathrm{H}_{2} \mathrm{O} / \mathrm{Lf}$ or TA. The wavelength for recording chromatograms was $258 \mathrm{~nm}$ for $\mathrm{AOH}$ and AME, and $280 \mathrm{~nm}$ for TA. The calibration curve was constructed using the toxins standard and correlating peak-area versus the mass of analyte injected. Reference spectra were acquired during the elution of the associated standards and used for peak identification by comparison after spectra normalization. The detection limits were $11 \mu \mathrm{g} / \mathrm{kg}$ for TA, $2 \mu \mathrm{g} / \mathrm{kg}$ for AME to $5 \mu \mathrm{g} /$ $\mathrm{kg}$ for $\mathrm{AOH}$.

\section{Results}

\subsection{Production profiles of secondary metabolites}

The toxigenic profile of the 50 Alternaria isolates from Argentinean Malbec grapes is shown in Table 1. TA, AOH and AME production was tested. All the isolates were able to produce mycotoxins. TA was produced by $100 \%(50 / 50)$ in a range from 0.016 to $21.031 \mathrm{mg} / \mathrm{kg}$. AOH was produced by $98 \%(49 / 50)$ in a range from 0.003 to $0.057 \mathrm{mg} / \mathrm{kg}$. AME production was observed in $36 \%(18 / 50)$ in a range from 0.001 to $0.133 \mathrm{mg} / \mathrm{kg}$. TA was the toxin produced at higher levels.

\subsection{Co-production of secondary metabolites}

The co-production of mycotoxins is shown in Fig. 1. A $36 \%$ of the isolates (18/50) co-produced the three mycotoxins, $62 \%(31 / 50)$ simultaneously produced $\mathrm{TA}$ and $\mathrm{AOH}$. One isolate produced only one mycotoxin (TA).

Table 1. Production of Alternaria mycotoxins.

\begin{tabular}{|c|c|c|c|c|c|}
\hline \multirow[t]{2}{*}{ Species } & \multirow[t]{2}{*}{ No. of isolates } & \multicolumn{4}{|c|}{ Mycotoxin production } \\
\hline & & Mycotoxin & No. of positive & Average (mg/kg) & Range (mg/kg) \\
\hline \multirow[t]{3}{*}{ A. tenuissima } & $40(78.4 \%)$ & TA & 40 & 3.195 & 0.016-21.031 \\
\hline & & $\mathrm{AOH}$ & 39 & 0.013 & $0.003-0.057$ \\
\hline & & AME & 14 & 0.052 & $0.001-0.133$ \\
\hline \multirow[t]{3}{*}{ A. alternata } & $5(9.8 \%)$ & TA & 5 & 3.227 & $0.019-10.093$ \\
\hline & & $\mathrm{AOH}$ & 5 & 0.007 & $0.003-0.016$ \\
\hline & & AME & 2 & 0.021 & $0.020-0.022$ \\
\hline \multirow[t]{3}{*}{ A. arborescens } & $5(9.8 \%)$ & TA & 5 & 1.551 & $0.016-3.587$ \\
\hline & & $\mathrm{AOH}$ & 5 & 0.009 & $0.003-0.018$ \\
\hline & & AME & 2 & 0.017 & 0.017 \\
\hline
\end{tabular}




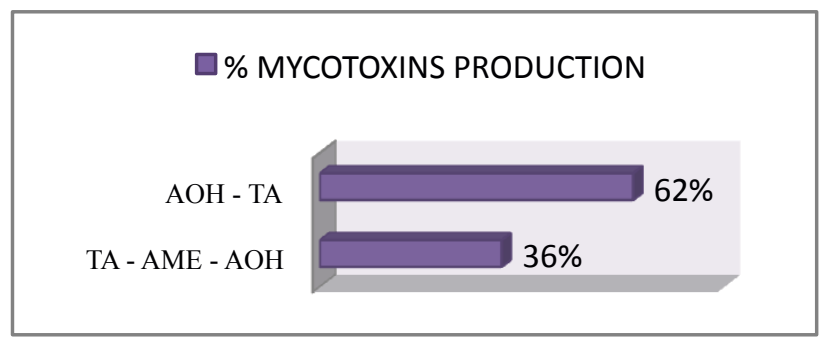

Figure 1. Co-production of Alternaria toxins.

\section{Discussion}

Alternaria growth on grapes has been reported in several countries such as Argentina, Brazil, Spain, Italy, Portugal, USA, Slovakia, Hungary and Czech Republic. The incidence of Alternaria in grapes has been reported in different percentages with respect to total mycobiota: 5-23\% in USA, $25 \%$ in Italy, $80 \%$ in Argentina; 3-18\%, $24 \%, 17 \%$ in different studies in Portugal, 75\%, 3-58\%, $13 \%$ in Spain, and A. alternata and A. tenuissima were reported in 16-19\% in Slovakia [7,8,13,15,24,25,35-42].

A decrease in the percentage of grapes contaminated with Alternaria spp. was observed with the maturation of the berries [36,37,39,41]; however in Slovenia, A. alternata increased its incidence in 2008 and decreased in 2009; while the incidence of A. tenuissima was maintained in 2008 and declined in 2009 [13].

Even though the occurrence of AOH, AME and TA has been reported in wine [46-48], the presence of Alternaria isolates in the vineyard, harvest or post-harvest could not be correlated with the presence of mycotoxins in wine due to the lack of studies.

Few studies are available in the literature on the toxigenic profile of Alternaria species isolated from grapes. In this study, the production profiles of the most common Alternaria mycotoxins (TA, AOH and AME) isolated from Malbec grapes were determined. TA was the toxin produced at the highest concentration. This result demonstrates a lower production of Alternaria toxins compared to strains isolated from different substrates as Argentine wheat, blueberries and tomatoes [34,43-45].

Autoclaved rice was used as a substrate for mycotoxins testing of Alternaria, following the method described by $\mathrm{Li}$ et al. [34]. This substrate is suitable for the mycotoxins biosynthesis because mechanical barriers and grains defenses, which are thermolabile, have been suppressed, thus allowing Alternaria isolates to express their toxicogenic potential in the substrate analyzed [43]. It is necessary to evaluate the toxicogenic capacity in grapes or a media that representing this substrate to know the real potential risk of these mycotoxins.

\section{Conclusion}

The present work shows the toxigenic potential of the Alternaria species isolated from Malbec grapes, which indicates the potential risk of mycotoxin accumulation in the fruits. More work should be done to assess the health risk implied by the presence of Alternaria toxins in grapes, musts, wines, spirits, and raisins, since there is little information in Argentina and worldwide. The only mycotoxin regulated in wines is ochratoxin A, while there are not regulations for $\mathrm{AOH}, \mathrm{AME}$ and TA. Grape producers should be advised to prevent fungal growth and mycotoxin contamination.

\section{References}

[1] JM. Aurand, Actas del 37 Congreso Mundial de la Viña y el Vino (2014)

[2] J. Pitt, A.D. Hocking. Fungi and Food spoilage. Blackie Academic and Professional. London (1997)

[3] B. Pryor, T. Michailides, The American Phytopathology Society 92, 406-416 (2002)

[4] R. Polizzotto, B. Andersen, M. Martini, S. Grisan, G. Assante, R. Musetti, J. Microbiol. Methods 88, 162-171 (2012)

[5] F. Rotondo, M. Collina, A. Brunelli, B. Pryor, The American Phytopathology Society 102, 1130-1142 (2012)

[6] E. Van de Perre, N. Deschuyffeleer, L. Jacxsens, F. Vekeman, W. Van Der Hauwaert, S. Asam, et al. Food Control 37, 165-170 (2014)

[7] M. Lorenzini, G. Zapparoli. Int J Food Microbiol. 186, 1-5 (2014)

[8] R. Serra, A. Lourenco, P. Alipio, A. Venancio, MycologicalResearch 110, 971-978 (2006)

[9] S. Romero, R. Comerio, G. Larumbe, A. Ritieni, G. Vaamonde, V. Fernández, Int J Food Microbiol. 104, 43-49 (2005)

[10] A. Swart, C. Lennox, G. Holz, S. Afr. J. Enol. Vitic. 16, 3-6 (1995)

[11] L. Mostert, P. Crous, O. Petrini, Sydowia 52, 46-58 (2000)

[12] J. Chunmei, S. Junling, H. Qian, L. Yanlin, Food Control 31, 5-13 (2013)

[13] P. Mikusová, A. Santini, A. Ritieni, J. Pavlokin, A. Srobárová, Rev IberoamMicol. 29(3),126-131 (2012)

[14] M. Bragulat, M. Abarca, F. Cabañes, LettAppl Microbiol 47, 286-289 (2008)

[15] J. Varga, Z. Koncz, S. Kocsubé, T. Mátrai, J. Téren, V. Ostry, et al. Acta Alimentaria 36(3), 329-341 (2007)

[16] C. Gómez, M. Bragulat, M. Abarca, S. Mínguez, F. Cabañes, Food Microbiol 23, 541-545 (2006)

[17] N. Belli, D. Mitchell, S. Marrín, I. Alegre, A. Ramos, N. Mangan, V. Sanchis, Eur. J. Plant Pathol. 113, 233-239 (2005)

[18] S. Leong, A. Hocking, J. Pitt, Aust. J. Grape Wine Res. 10, 83-88 (2004)

[19] M. Chiotta, A. Susca, G. Stea, G. Mulè, G. Perrone, A. Logrieco, S. Chulze, Int J Food Microbiol. 149, 171-176 (2011)

[20] M. Chiotta, M. Ponsone, M. Combina, A. Torres, S. Chulze, Int J Food Microbiol. 136, 137-141 (2009)

[21] A. Astoreca, C. Magnoli, C. Barberis, S. Chiacchiera, M. Combina, A. Dalcero, Sci Total Environ. 3880, 16-23 (2007)

[22] A. Donoso, B. Latorre, Cien. Inv. Agr. 33(2), 143-155 (2006)

[23] J. Franck, B. Latorre, R. Torres, J. Zoffoli, Postharvest Biol. Technol. 37, 20-30 (2005)

[24] C. Magnoli, M. Violante, M. Combina, G. Palacio, A. Dalcero, Lett Appl Microbiol. 37, 179-184 (2003) 
[25] C. Da Rocha Rosa, V. Palacios, M. Combina, M. Fraga, A. Oliveira, C. Magnoli, et al. Food Addit Contam. 19, 408-414 (2002).

[26] B. Andersen, E. Krøger, R. Roberts, Mycological Research 106(2), 170-182 (2002)

[27] V. Ostry, World Mycotoxin Journal 1(2), 175-188 (2008)

[28] L. Terminiello, A. Patriarca, G. Pose, V. Fernández Pinto, Mycotoxin Research 22(4), 236-240 (2006)

[29] M. Azcarate, A. Patriarca, L. Terminiello, V. Fernández Pinto, J. Food Prot. 71(6), 1262-1265 (2008)

[30] A. Visconti, A. Sibilia, Alternariatoxins. In: Miller, J.D. y Trenholm, H.L. (Eds.) Mycotoxins in grain. Eagan Press, St. Paul, MN, USA; 315-336 (1994)

[31] S. Da Motta, L. Valente, Braz J Microbiol. 31, 315-320 (2000)

[32] A. Logrieco, A. Moretti, M. Solfrizzo, World Mycotoxin Journal 2(2), 129-140 (2009)

[33] A. Vargas, F. Quevedo, V. Fernández Pinto Virginia, A. Patriarca, Actas del 37 Congreso Mundial de la Vid y el Vino 412-413 (2014)

[34] F. Li, N. Toyazaki, T. Yoshizawa, J. Food Prot. 64, 567-571 (2001)

[35] L. Abrunhosa, R. Paterson, Z. Kozakiewicz, N. Lima, A. Venancio, Lett Appl Microbiol. 32, 240-242 (2001)

[36] R. Serra, A. Braga, A. Venancio, Research in Microbiology 156, 515-521 (2005)
[37] M. Bau, M. Bragulat, M. Abarca, S. Minguez, F. Cabañes, Int J Food Microbiol. 98, 125-130 (2005)

[38] A. Medina, R. Mateo, L. López-Ocaña, F. ValleAlgarra, M. Jiménez, Applied and Environmental Microbiology Aug, 4696-4702 (2005)

[39] C. Gomez, M. Bragulat, M. abarca, S. Mínguez, F. Cabañes, Food Microbiology 23, 541-545 (2006)

[40] V. Tournas, E. Katsoudas, Int J Food Microbiol. 105, 11-17 (2005)

[41] N. Bellí, M. Bau, S. Marín, M. Abarca, A. Ramos, M. Bragulat, Int J Food Microbiol. 111, S40-S45 (2006)

[42] M. Lorenzini, M. Azzolini, E. Tosi, G. Zapparoli, Journal of Applied Microbiology 114, 762-770 (2012)

[43] A. Patriarca, M. Azcarate, L. Terminiello, V. Fernández Pinto, Int J Food Microbiol. 119, 219-222 (2007)

[44] G. Pose, V. Ludemann, J. Segura, V. Fernández Pinto, Mycotoxin Research 20, 80-86 (2004)

[45] M. Greco, A. Patriarca, L. Terminiello, V. Fernández Pinto, Int J Food Microbiol. 154, 187-191 (2012)

[46] L. Broggi, C. Reynoso, S. Resnick, F. Martinez, V. Drunday, A. Romero Bernal, Mycotoxin Research 29(1), 17-22 (2013)

[47] S. Asam, K. Konitzer, P. Schieberle, M. Rychlik, J. Agric. Food Chem. 57(12), 5152-5160 (2009)

[48] P. Scott, G. Lawrence, B. Lau, Mycotoxin Research 22(2), 142-147 (2006) 